\title{
LPS inmobilization on porous and non-porous supports as an approach for the isolation of anti-LPS host-defense peptides
}

\author{
Carlos López-Abarrategui ${ }^{1}$, Alberto del Monte-Martínez ${ }^{1}$, Osvaldo Reyes-Acosta ${ }^{2}$, Octavio L. Franco ${ }^{3}$ \\ and Anselmo J. Otero-González ${ }^{1}$ * \\ ${ }^{1}$ Center for Protein Studies, Faculty of Biology, University of Havana, Havana, Cuba \\ ${ }^{2}$ Center for Genetic Engineering and Biotechnology, Havana, Cuba \\ ${ }^{3}$ Centro de Análises Proteômicas e Bioquímicas, Programa de Pós-Graduação em Ciências Genômicas e Biotecnologia, Universidade Católica de Brasília, \\ Brasília, Brazil
}

Edited by:

Nádia Skorupa Parachin, Universidade de Brasília, Brazil

Reviewed by:

Attila Gacser, University of Szeged, Hungary

Etinosa Igbinosa, University of Benin, Nigeria

Marc Torrent, MRC Laboratory of

Molecular Biology, UK

*Correspondence:

Anselmo J. Otero-González, Center for Protein Studies, Faculty of Biology, University of Havana, Calle $25 \times \mathrm{J}$,

Havana, Cuba

e-mail: aoterog@infomed.sld.cu
Lipopolysaccharides (LPSs) are the major molecular component of the outer membrane of Gram-negative bacteria. This molecule is recognized as a sign of bacterial infection, responsible for the development of local inflammatory response and, in extreme cases, septic shock. Unfortunately, despite substantial advances in the pathophysiology of sepsis, there is no efficacious therapy against this syndrome yet. As a consequence, septic shock syndrome continues to increase, reaching mortality rates over $50 \%$ in some cases. Even though many preclinical studies and clinical trials have been conducted, there is no Food and Drug Administration-approved drug yet that interacts directly against LPS. Cationic host-defense peptides (HDPs) could be an alternative solution since they possess both antimicrobial and antiseptic properties. HDPs are small, positively charged peptides which are evolutionarily conserved components of the innate immune response. In fact, binding to diverse chemotypes of LPS and inhibition of LPS-induced pro-inflammatory cytokines from macrophages have been demonstrated for different HDPs. Curiously, none of them have been isolated by their affinity to LPS. A diversity of supports could be useful for such biological interaction and suitable for isolating HDPs that recognize LPS. This approach could expand the rational search for anti-LPS HDPs.

Keywords: LPS, antiendotoxic, antimicrobial peptides, affinity chromatography, LPS immobilization

\section{INTRODUCTION}

Sepsis is characterized by an uncontrolled inflammatory as well as anti-inflammatory process driven by the host immune system in response to bacteria (Adib-Conquy and Cavaillon, 2012). This syndrome is one of the leading causes of death in intensive care units worldwide and its incidence is progressively increasing (Kotsaki and Giamarellos-Bourboulis, 2012). Although major wall components of Gram-positive bacteria (peptidoglycan and lipoteichoc acid) can induce sepsis, the highest incidence of this syndrome is caused by lipopolysaccharides (LPSs) from Gramnegative bacteria (De Kimpe et al., 1995). Consequently, research in this field has been focused on LPS. LPSs are the major molecular component of the outer membrane of Gram-negative bacteria. This molecule represents a pathogen-associated molecular pattern (PAMP), responsible for the development of local inflammatory response through Toll-like receptor-4 (TLR-4) signaling (Miller etal., 2005). The inflammatory response is essential for bacterial clearence, but in extreme cases an exacerbated reaction may lead to septic shock (Salomao et al., 2012). Unfortunately, despite substantial advances in the pathophysiology of sepsis, there is no efficacious therapy against this syndrome yet (Schulte et al., 2013). As a consequence, septic shock syndrome continues to increase, reaching mortality rates over $50 \%$ in some cases (Buttenschoen et al., 2010).
In this context, the search for new therapeutics that can inhibit the activation of the innate immune system by LPS is of major importance (Pulido etal., 2012). Even though many studies in animal models and clinical trials have been conducted, there is no effective drug yet that interacts directly against LPS (Buttenschoen et al., 2010). Host-defense peptides (HDPs) could be a possible alternative solution since they possess antimicrobial, antiseptic, and immunomodulatory properties (Giuliani et al., 2010). These molecules have been identified as a defense strategy across many forms of life from prokaryotic organisms to vertebrates (Zasloff, 2002). HDPs are generally small, commonly having around 12-50 amino acid residues, cationic (net charge of +2 to +7 ), and are frequently quite hydrophobic and amphipathic (Jenssen etal., 2006). Furthermore, binding to diverse chemotypes of LPS and inhibition of LPS-induced pro-inflammatory cytokines from macrophages have been demonstrated for different HDPs (Scott et al., 2000; Lee etal., 2010). Interestingly, none of them have been isolated taking advantage of their affinity to LPS. As the search for new LPS-binding peptides is imperative for the development of more effective therapies, the use of LPS immobilized on different supports could be useful and suitable for isolating them. This approach could expand the rational search for anti-LPS HDPs. 


\section{LIPOPOLYSACCHARIDE ENDOTOXIN}

Lipopolysaccharides are the major molecular component of the outer membrane of Gram-negative bacteria. This molecule is essential for the survival of Gram-negative bacteria, contributing to the correct assembly of the outer membrane. In this context, LPS provides a permeability barrier to many different classes of molecules such as detergents, antibiotics, and metals. Due to their localization, LPS molecules participate in host-bacterium interactions like adhesion, colonization, virulence, and symbiosis (Silipo and Molinaro, 2011).

Lipopolysaccharide is an amphiphilic molecule composed of three domains: lipid A, core oligosaccharide, and O-antigen repeats. Lipid A represents the hydrophobic component of LPS, which is located in the outer leaflet of the outer membrane and carries the endotoxic properties of LPS. This domain is the most conserved region of the lipopolysaccharide molecule. The hydrophilic portion of the molecule is composed of the glycan, $\mathrm{O}$ antigen. The core oligosaccharide joins the lipid A and $\mathrm{O}$-antigen domains. The core oligosaccharide domain can be divided into two regions: the inner core (proximal to lipid A) and the outer core (proximal to $\mathrm{O}$-antigen). In contrast to lipid A, core oligosaccharide and $\mathrm{O}$-antigen domains are displayed on the surface of bacteria (Brandenburg et al., 2010).

The activation of the immune system by LPS occurs through the transmembrane protein TLR-4, a pattern recognition receptor (PRR) found on the surface of many cells from the innate immune system. MD-2, a small membrane-bound glycoprotein, associates with TLR-4 for the recognition of LPS. Other proteins such as CD14 and LPS-binding protein (LBP) enable the interaction of LPS with MD-2. After LPS recognition, TLR4 homodimerises, initiating the recruitment of intracellular adapter molecules such as MyD88, Mal, Trif, and Tram and leading to the expression of diverse inflammatory genes (Miller et al., 2005; Bryant et al., 2010; Mcgettrick and O’Neill, 2010).

\section{ANTI-LIPOPOLYSACCHARIDE HOST-DEFENSE PEPTIDES}

The efficacy of HDPs against Gram-negative bacteria has been widely documented (Vaara, 2009; Cao et al., 2010; Park et al., 2011). The antimicrobial activity of these molecules is not only a consequence of their direct action against bacteria (at the cellular membrane and/or intracellular targets) but also of their anti-infective (modulation of the immune system) capacity (Hale and Hancock, 2007; Wieczorek et al., 2010). Although the outer membrane of Gram-negative bacteria constitutes an excellent permeability barrier to antibacterial agents, the interaction of HDPs with LPS permits this resistance mechanism to be bypassed. The process by HDPs across the outer membrane has been termed self-promoted uptake (Sawyer et al., 1988). In this mechanism, the peptides firstly interact with the negative surface of LPS and competitively displace the divalent cations that bridge the LPS barrier. This causes disturbance of the outer membrane, promoting peptide movement through it.

Host-defense peptides are very attractive molecules for use as therapeutics against septic syndrome due to their affinity for LPS and their antibacterial activity (Pulido et al., 2012). In fact, a number of natural HDPs from various sources bind to diverse chemotypes of LPS and reduce LPS-induced release of pro-inflammatory cytokines (Bowdish and Hancock, 2005; Bhattacharjya, 2010). For example, in vitro and in vivo LPS neutralization by the human cathelicidin peptide LL-37 has been demonstrated (Scott et al., 2002). The pretreatment of monocytes with this peptide inhibited Pseudomonas aeruginosa LPS-induced IL- 8 production.

Interestingly, pro-inflammatory cytokine inhibition was abolished upon removal of LL-37 from the media before LPS stimulation, suggesting that the capacity of LL-37 to inhibit LPS signalling is dependent on extracellular LPS neutralization (Scott et al., 2011). Nevertheless, LL-37 may also have direct effects on macrophage function. Scott et al. (2002) demonstrated the upregulation of 29 genes and downregulation of another 20 genes in macrophages treated with the peptide using gene expression profiling experiments. Among the genes predicted to be up-regulated by LL-37 were those encoding chemokines and chemokine receptors, without stimulating the pro-inflammatory cytokine, TNF- $\alpha$. Furthermore, an intracellular receptor for this peptide in monocytes has been discovered (Mookherjee et al., 2009). In order to increase the antiendotoxic activity of LL-37, various cathelicidinderived peptides have been studied (Nagaoka et al., 2002; Nell et al., 2005). The antiendotoxic activity can be improved by increasing the hydrophobicity and cationicity of the parental peptide (Nagaoka et al., 2002). The LPS neutralization capacity of cathelicidins from another species has also been proved (Tossi et al., 1994; Tack et al., 2002; Bhunia et al., 2009).

Although the LPS neutralization properties of $\alpha$-defensins are low (Scott et al., 2000), a potent antiendotoxic activity for some $\beta$ defensins has been established (Motzkus et al., 2006). Indeed, it has recently been demonstrated that LPS-binding activity and TNF- $\alpha$ release inhibition in RAW264.7 cultures for the human $\beta$-defensin DEFB114. Additionally, protection against LPS-induced reduction of human sperm motility in vitro and LPS-induced lethality of D-galactosamine-sensitized C57BL/6 mice were also demonstrated for DEFB114 (Yu et al., 2013). The antiendotoxic activity of DEFB1 14 was dependent on disulfide bond. On the other hand, fluorescence experiments demonstrated that DEFB126, another human $\beta$-defensin with anti-sepsis activity, can penetrate RAW 264.7 cells and diminish the production of LPS-stimulated inflammatory factors. In the same way, DEFB126 might also participate in intracellular immune regulation beyond its direct LPS neutralization (Liu et al., 2013). Perhaps DEFB126 uses a similar intracellular pathway to that of LL-37. Moreover, the differences in the antiendotoxic activity between $\alpha$-defensins and $\beta$-defensins suggested that antibacterial activities do not necessarily correlate with anti-LPS properties (Bhattacharjya, 2010). Finally, the anti-LPS properties of invertebrate defensins have also been demonstrated (Saido-Sakanaka et al., 2004; Koyama et al., 2006). Other HDPs also have the capacity to inhibit LPS effects (Jacks et al., 1996; Giacometti et al., 2006; Lin et al., 2013; Schadich et al., 2013). These examples evidence the natural role of HDPs in the defense against LPS-induced septic shock.

Different mechanisms of LPS inhibition have been described for HDPs (Pulido et al., 2012). In general, the direct interaction of HDPs can disaggregate, or induce a change in the unilamellar/cubic structure of LPS to multilamellar, inhibiting the recognition of this molecule by the immune receptor complex 
(Andra et al., 2005; Kaconis et al., 2011; Singh et al., 2013). Besides, HDPs also can inhibit LPS-induced sepsis by their modulation of immune cells. In this context, the inhibition of pro-inflammatory mediators (Liu et al., 2013), inhibition of surface expression of TLR-4 by interacting with microtubules (Li et al., 2013), and the normalization of the coagulation (Kalle et al., 2012) have been demonstrated.

Otherwise, the structural knowledge of LPS-high affinity binders such as Limulus anti-LPS factor (Hoess et al., 1993), Bactericidal/permeability-increasing protein (Beamer et al., 1997), Factor C (Tan etal., 2000) and Polymyxin B (Pristovsek and Kidric, 1999) among others has allowed the development of synthetic antiendotoxic peptides (Pristovsek and Kidric, 2001; Andra et al., 2006; Ding et al., 2008). Although preclinical data are very encouraging, only one of the synthetic variants, the recombinant fragment of protein BPI (rBPI21), has been tested successfully in clinical studies (Domingues etal., 2012). The situation is similar for natural compounds where there is no Food and Drug Administration (FDA)-approved drug yet that interacts directly against LPS. Only the apheresis procedures for endotoxin adsorption with Polymyxin B (lipopeptide produced by the bacterium Bacillus polymyxa) immobilized in the fiber column have been used for the treatment of septic shock patients in Japan since 1994 (Ruberto etal., 2013). Due to the failure to obtain antiendotoxic molecules with clinical efficacy, searching for new LPS-binding peptides is imperative (Giuliani et al., 2010).

\section{LIPOPOLYSACCHARIDE IMMOBILIZATION}

Affinity chromatography is one of the most efficient protein purification strategies. This technique is a method for selective purification of molecules from complex mixtures based on highly specific biological interaction between the immobilized ligand and the molecule of interest. The highly selective interactions that guide this procedure allow for a fast, often single-step process, with potential for purification in the order of several hundred to 1000 -fold (Urh et al., 2009). Successful affinity purification is determined by the selection of a suitable support and immobilized ligand. The affinity support (the matrix onto which the ligand is immobilized) should selectively capture the molecule of interest while at the same time exhibiting low non-specific adsorption (Gustavsson and Larsson, 2006).

\section{ISOLATION OF LIPOPOLYSACCHARIDE-BINDING PROTEINS}

Affinity supports based on LPS immobilization could be a powerful tool for the isolation of anti-LPS HDPs. Indeed, the isolation of LBPs using these supports has been described (Minetti et al., 1991; Chiou et al., 2000; Shahriar et al., 2006). For instance, the Limulus endotoxin-binding protein-protease inhibitor (LEBP-PI), a $12 \mathrm{kDa}$ protein from Limulus amebocytes, was purified using an LPS affinity column. In this study, the authors immobilized LPSs onto Affi-Gel Hz support (Bio-Rad). This support is based on hydrazide coupling chemistry. Affi-Gel $\mathrm{Hz}$ hydrazide gel is an agarose support which reacts with the aldehydes of oxidized carbohydrates (periodate oxidation) to form stable, covalent hydrazone bonds (O'Shannessy and Wilchek, 1990). A high yield of active LEBP-PI was achieved after elution with LPS or sodium citrate
(Minetti etal., 1991). On the other hand, Chiou et al. (2000) isolated an LBP by affinity chromatography based on LPS from Escherichia coli O55:B5 coupled to cyanogen bromide (CNBr) activated Sepharose CL-4B. The isolated glycoprotein showed an apparent molecular mass of about $40 \mathrm{kDa}$ and $72.2 \%$ identity to tachylectin-3, a lectin isolated from the amebocyte of T. tridentatus, previously characterized by its affinity to the $\mathrm{O}$-antigen of LPS. Shahriar et al. (2006) also used LPS-affinity chromatography for isolation of LBPs in porcine milk. The affinity support was prepared by coupling $100 \mathrm{mg}$ of E. coli F4 LPS - 3 g of CNBr-activated Sepharose 4B. Low affinity LBPs were eluted using mild conditions (Tris $10 \mathrm{mM}, 1 \mathrm{M} \mathrm{NaCl}, \mathrm{pH}$ 7.2) whereas high affinity binders were eluted using $0.1 \mathrm{M}$ glycine- $\mathrm{HCl}, \mathrm{pH} 2.5$. The LBPs lactoferrin, soluble CD14, serum amyloid A, alphaS1 casein, beta-casein, and kappa-casein were isolated by this approach. The coupling reagent used in the last two examples for synthesizing the affinity support was $\mathrm{CNBr}$, which is very efficient for immobilizing proteins. It activates hydroxyl groups on the resin to create reactive cyanate esters, which then can be coupled to amine-containing ligands forming an isourea bond (Urh et al., 2009). The LPS molecule is thus immobilized on these resins by their hexosamines located at the core outer region and in lipid A.

\section{ISOLATION OF LIPOPOLYSACCHARIDE-NEUTRALIZING PEPTIDES}

Despite the success in purifying LBPs by affinity chromatography, this approach has not yet been used for isolating anti-LPS HDPs. The idea that interaction of LPS and anti-LPS peptides could be affected when one of them is immobilized on a matrix is possible, and therefore isolating anti-LPS peptides with immobilized LPS could be less efficient. Nevertheless, an interesting attempt to study LPS interaction with anti-LPS peptides when the latter were immobilized (Gustafsson et al., 2010) showed that immobilization of HDPs does not inhibit their capacity to neutralize LPS, although there are differences between the peptides assayed. The interaction of LPS with immobilized peptides was efficient both in LPS binding and inhibiting cytokine production induced by LPS.

Otherwise, the binding of HDPs to LPS occurs through the lipid A moiety: specifically, basic aminoacids interact with phosphates and hydrophobic aminoacids with the acyl chains (Bhattacharjya et al., 2007). For this reason, the immobilization of LPS using hexosamines located in the lipid A region may affect recognition by HDPs. Therefore, a conjugation method keeping free the lipid A moiety in the lipopolysaccharide molecule could be more efficient to immobilize LPS for the isolation of anti-LPS HDPs. In fact, Pallarola and Battaglini $(2008,2009)$ performed the coupling of LPS with probes bearing hydrazine or primary amino groups. LPS was modified through the activation of the hydroxyl groups present in its $\mathrm{O}$-antigen moiety. Conjugates with good labeling ratios were obtained with the preservation of its endotoxic activity. A similar strategy was discussed above for the purification of LEBP-PI (Minetti et al., 1991). Otherwise, LPS molecules are capable of form micelles and aggregates even at very low concentrations (Yu et al., 2006). For this reason, the efficiency of LPS immobilization could be extremely low. Unfortunately, there is no data reported about the efficiency of LPS immobilization. Moreover, the coupling of LPS through the O-antigen domain may render a 


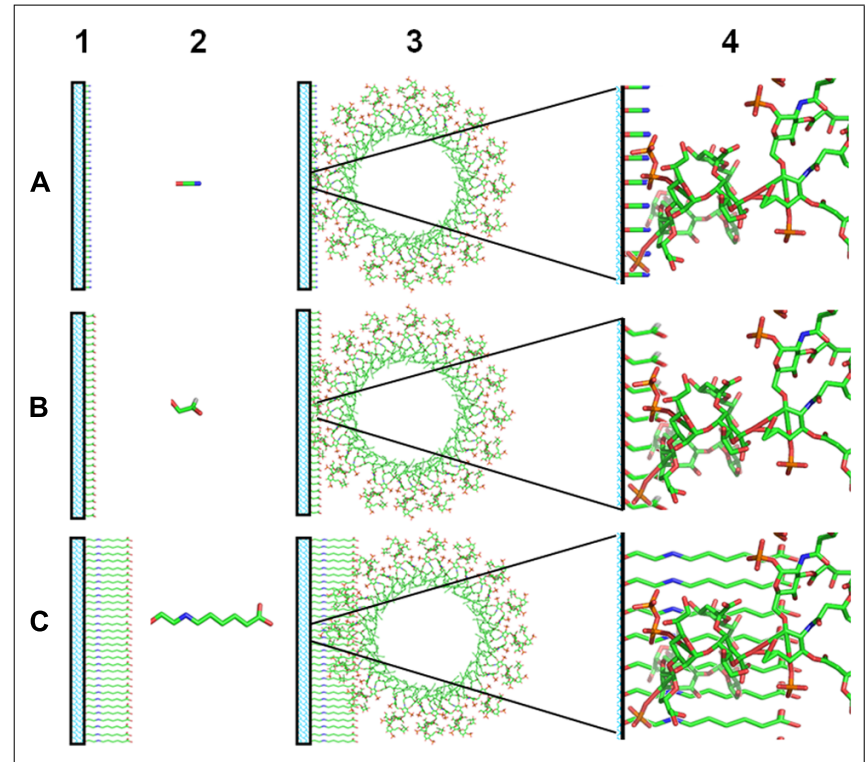

FIGURE 1 | Scheme of LPS immobilization on affinity supports. (1) Activated supports. (2) Coupling reagents. (3) Miscellar lipid A immobilized on affinity supports. (4) Zoom of the interaction of lipid A with the activated supports. (A) Cyanogen bromide activated support. (B) Glyoxyl activated support. (C) Ethyloxy-6-aminocaproic acid activated support.

higher immobilization efficiency than coupling LPS through hexosamines due to the poor reactivity of the latter (Eller et al., 2000). Nevertheless, the LPS immobilization through hexosamines could not be discarded due the large numbers of commercial resins that could be activated to react with amine groups (Urh et al., 2009). In this sense, the accurate use of coupling reagents may influences on the LPS affinity support synthesis. For example, coupling reagents with a higher length seems to better interact with LPS (Figure 1).

On the other hand, magnetic field-based separations using magnetic nanoparticles have received considerable attention in the last two decades (Horak et al., 2007). This methodology can be used on viscous materials, simplifying the purification process by removing sample pretreatment. Furthermore, the highly specific surface area of the nanoparticles enables the immobilization of a larger amount of molecule. Therefore, the immobilization of LPS on magnetic nanoparticles could be a very attractive procedure for isolating anti-LPS HDPs by magnetic separation. Although this approach has not been used yet, there are different examples of LPS immobilization on magnetic nanoparticles (Fornara et al., 2008; Piazza et al., 2011). For example, LPS was reversibly immobilized in a magnetic nanoparticle system consisting of oleylaminecoated iron oxide nanocrystals by hydrophobic interactions. LPS-magnetic nanoparticles were stable enough to mimic natural LPS aggregates for investigating the interaction of the LPS with TLR4 receptor (Piazza et al., 2011). In another approach, Fornara et al. (2008) synthesized magnetic nanoparticles for detection of Brucella antibodies in biological samples. Thermally blocked nanoparticles obtained by thermal hydrolysis were functionalized with LPS from Brucella abortus. LPS was attached to magnetic nanoparticles by adsorption through hydrophobic interactions, and the variation in magnetic relaxation due to surface binding of antibodies to LPS-functionalized nanoparticles was used to detect the disease. This method showed high sensitivity, with detection limit of $0.05 \mu \mathrm{g} / \mathrm{mL}$ of antibody in the biological samples without any pretreatment. Interestingly, the same approach could be used for detecting anti-LBPs from different sources. The same principle is not feasible for HDPs due to their small molecular weight. Furthermore, both systems described above could be used as affinity purification procedures, but the stability of hydrophobic LPS-functionalized nanoparticles in drastic elution conditions ( $0.1 \mathrm{M}$ glycine- $\mathrm{HCl}, \mathrm{pH} 2.5)$ would have to be evaluated.

As was exemplified above, the synthesis of affinity supports is no longer used only for purification of specific biomolecules. It is also rapidly becoming a method of choice to study biological interactions. In fact, Genfa et al. (2005) identified LPS-binding molecules in herb fractions by coating affinity optical biosensor cuvettes with lipid A via hydrophobic interactions after pre-incubating extracts with LPS. Such a concept demonstrated that LPS can be immobilized, keeping its ability to efficiently bind LPS binding molecules, and it could represent a high-throughput approach for the identification of LPS-neutralizing peptides (Zheng et al., 2010).

\section{CONCLUDING REMARKS}

Despite substantial advances in the pathophysiology of sepsis, there is no effective therapy against this syndrome yet. A therapeutic alternative could be the use of HDPs due to the capacity of some of them to neutralize LPS. As it is vital to find new LPSbinding peptides for the development of more effective therapies, the use of LPS immobilized on different supports could be useful and suitable for isolating them. This approach could expand the rational search for anti-LPS HDPs.

\section{ACKNOWLEDGMENTS}

We would like to thank the International Foundation of Science (IFS), Sweden, for financial support (project IFS F 5199). Furthermore, authors also thanks to Conselho Nacional de Desenvolvimento Cientifico e Tecnologico (CNPq), Coordenação de Aperfeiçoamento de Pessoal de Nivel Superior (CAPES) and Fundação de Apoio a Pesquisa do Distrito Federal (FAPDF).

\section{REFERENCES}

Adib-Conquy, M., and Cavaillon, J. M. (2012). [Host inflammatory and antiinflammatory response during sepsis]. Pathol. Biol. (Paris) 60, 306-313. doi: 10.1016/j.patbio.2012.03.011

Andra, J., Gutsmann, T., Garidel, P., and Brandenburg, K. (2006). Mechanisms of endotoxin neutralization by synthetic cationic compounds. J. Endotoxin. Res. 12, 261-277. doi: 10.1179/096805106X118852

Andra, J., Lohner, K., Blondelle, S. E., Jerala, R., Moriyon, I., Koch, M. H., et al. (2005). Enhancement of endotoxin neutralization by coupling of a C12alkyl chain to a lactoferricin-derived peptide. Biochem. J. 385, 135-143. doi: 10.1042/BJ20041270

Beamer, L. J., Carroll, S. F., and Eisenberg, D. (1997). Crystal structure of human BPI and two bound phospholipids at 2.4 angstrom resolution. Science 276, 1861-1864. doi: 10.1126 /science.276.5320.1861

Bhattacharjya, S. (2010). De novo designed lipopolysaccharide binding peptides: structure based development of antiendotoxic and antimicrobial drugs. Curr. Med. Chem. 17, 3080-3093. doi: 10.2174/092986710791959756 
Bhattacharjya, S., Domadia, P. N., Bhunia, A., Malladi, S., and David, S. A. (2007). High-resolution solution structure of a designed peptide bound to lipopolysaccharide: transferred nuclear Overhauser effects, micelle selectivity, and anti-endotoxic activity. Biochemistry 46, 5864-5874. doi: 10.1021/bi60 25159

Bhunia, A., Mohanram, H., and Bhattacharjya, S. (2009). Lipopolysaccharide bound structures of the active fragments of fowlicidin-1, a cathelicidin family of antimicrobial and antiendotoxic peptide from chicken, determined by transferred nuclear Overhauser effect spectroscopy. Biopolymers 92, 9-22. doi: 10.1002/bip.21104

Bowdish, D. M., and Hancock, R. E. (2005). Anti-endotoxin properties of cationic host defense peptides and proteins. J. Endotoxin. Res. 11, 230-236. doi: 10.1179/096805105X37394

Brandenburg, K., Schromm, A. B., and Gutsmann, T. (2010). Endotoxins: relationship between structure, function, and activity. Subcell. Biochem. 53, 53-67. doi: 10.1007/978-90-481-9078-2_3

Bryant, C. E., Spring, D. R., Gangloff, M., and Gay, N. J. (2010). The molecular basis of the host response to lipopolysaccharide. Nat. Rev. Microbiol. 8, 8-14. doi: 10.1038/nrmicro2266

Buttenschoen, K., Radermacher, P., and Bracht, H. (2010). Endotoxin elimination in sepsis: physiology and therapeutic application. Langenbecks Arch. Surg. 395, 597-605. doi: 10.1007/s00423-010-0658-6

Cao, Y., Yu, R. Q., Liu, Y., Zhou, H. X., Song, L. L., Cao, Y., et al. (2010). Design, recombinant expression, and antibacterial activity of the cecropinsmelittin hybrid antimicrobial peptides. Curr. Microbiol. 61, 169-175. doi: 10.1007/s00284-010-9592-7

Chiou, S. T., Chen, Y. W., Chen, S. C., Chao, C. F., and Liu, T. Y. (2000). Isolation and characterization of proteins that bind to galactose, lipopolysaccharide of Escherichia coli, and protein A of Staphylococcus aureus from the hemolymph of Tachypleus tridentatus. J. Biol. Chem. 275, 1630-1634. doi: 10.1074/jbc.275.3.1630

De Kimpe, S. J., Kengatharan, M., Thiemermann, C., and Vane, J. R. (1995). The cell wall components peptidoglycan and lipoteichoic acid from Staphylococcus aureus act in synergy to cause shock and multiple organ failure. Proc. Natl. Acad. Sci. U.S.A. 92, 10359-10363. doi: 10.1073/pnas.92.22.10359

Ding, J. L., Li, P., and Ho, B. (2008). The sushi peptides: structural characterization and mode of action against Gram-negative bacteria. Cell. Mol. Life Sci. 65, 12021219. doi: 10.1007/s00018-008-7456-0

Domingues, M. M., Santos, N. C., and Castanho, M. A. (2012). Antimicrobial peptide rBPI21: a translational overview from bench to clinical studies. Curr. Protein Pept. Sci. 13, 611-619. doi: 10.2174/1389203711209070611

Eller, K., Henkes, E., Rossbacher, R., and Höke, H. (2000). "Amines, Aliphatic," in Ullmann's Encyclopedia of Industrial Chemistry (Weinheim: Wiley-VCH Verlag $\mathrm{GmbH} \& \mathrm{Co}$. KGaA).

Fornara, A., Johansson, P., Petersson, K., Gustafsson, S., Qin, J., Olsson, E., et al. (2008). Tailored magnetic nanoparticles for direct and sensitive detection of biomolecules in biological samples. Nano Lett. 8, 3423-3428. doi: $10.1021 /$ nl 8022498

Genfa, L., Jiang, Z., Hong, Z., Yimin, Z., Liangxi, W., Guo, W., et al. (2005). The screening and isolation of an effective anti-endotoxin monomer from Radix Paeoniae Rubra using affinity biosensor technology. Int. Immunopharmacol. 5, 1007-1017. doi: 10.1016/j.intimp.2005.01.013

Giacometti, A., Cirioni, O., Ghiselli, R., Mocchegiani, F., Orlando, F., Silvestri, C., et al. (2006). Interaction of antimicrobial peptide temporin $\mathrm{L}$ with lipopolysaccharide in vitro and in experimental rat models of septic shock caused by gram-negative bacteria. Antimicrob. Agents Chemother. 50, 2478-2486. doi: 10.1128/AAC.01553-05

Giuliani, A., Pirri, G., and Rinaldi, A. C. (2010). Antimicrobial peptides: the LPS connection. Methods Mol. Biol. 618, 137-154. doi: 10.1007/978-1-60761594-1_10

Gustafsson, A., Olin, A. I., and Ljunggren, L. (2010). LPS interactions with immobilized and soluble antimicrobial peptides. Scand. J. Clin. Lab. Invest. 70, 194-200. doi: 10.3109/00365511003663622

Gustavsson, P. E., and Larsson, P. O. (2006). "Support materials for affinity chromatography," in Handbook of Affinity Immobilization, ed. D.S. Hage (Boca Raton: CRC press/Taylor and Francis Group), 15-34.

Hale, J. D., and Hancock, R. E. (2007). Alternative mechanisms of action of cationic antimicrobial peptides on bacteria. Expert Rev. Anti. Infect. Ther. 5, 951-959. doi: $10.1586 / 14787210.5 .6 .951$
Hoess, A., Watson, S., Siber, G. R., and Liddington, R. (1993). Crystal structure of an endotoxin-neutralizing protein from the horseshoe crab, Limulus anti-LPS factor, at 1.5 A resolution. EMBO J. 12, 3351-3356.

Horak, D., Babic, M., Mackova, H., and Benes, M. J. (2007). Preparation and properties of magnetic nano- and microsized particles for biological and environmental separations. J. Sep. Sci. 30, 1751-1772. doi: 10.1002/jssc.200700088

Jacks, T. J., De Lucca, A. J., and Brogden, K. A. (1996). Interaction of lipopolysaccharide with the antimicrobial peptide "cecropin A". Adv. Exp. Med. Biol. 391, 357-360. doi: 10.1007/978-1-4613-0361-9_29

Jenssen, H., Hamill, P., and Hancock, R. E. (2006). Peptide antimicrobial agents. Clin. Microbiol. Rev. 19, 491-511. doi: 10.1128/CMR.00056-05

Kaconis, Y., Kowalski, I., Howe, J., Brauser, A., Richter, W., Razquin-Olazaran, I., et al. (2011). Biophysical mechanisms of endotoxin neutralization by cationic amphiphilic peptides. Biophys. J. 100, 2652-2661. doi: 10.1016/j.bpj.2011. 04.041

Kalle, M., Papareddy, P., Kasetty, G., Morgelin, M., Van Der Plas, M. J., Rydengard, V., et al. (2012). Host defense peptides of thrombin modulate inflammation and coagulation in endotoxin-mediated shock and Pseudomonas aeruginosa sepsis. PLoS ONE 7:e51313. doi: 10.1371/journal.pone.0051313

Kotsaki, A., and Giamarellos-Bourboulis, E. J. (2012). Emerging drugs for the treatment of sepsis. Expert Opin. Emerg. Drugs 17, 379-391. doi: 10.1517/14728214.2012.697151

Koyama, Y., Motobu, M., Hikosaka, K., Yamada, M., Nakamura, K., SaidoSakanaka, H., et al. (2006). Protective effects of antimicrobial peptides derived from the beetle Allomyrina dichotoma defensin on endotoxic shock in mice. Int Immunopharmacol. 6, 234-240. doi: 10.1016/j.intimp.2005.08.008

Lee, S. H., Jun, H. K., Lee, H. R., Chung, C. P., and Choi, B. K. (2010). Antibacterial and lipopolysaccharide (LPS)-neutralizing activity of human cationic antimicrobial peptides against periodontopathogens. Int. J. Antimicrob. Agents 35, 138-145. doi: 10.1016/j.ijantimicag.2009.09.024

Li, D., Liu, Y., Yang, Y., Chen, J. H., Yang, J., Zou, L. Y., et al. (2013). Looped host defense peptide CLP-19 binds to microtubules and inhibits surface expression of TLR4 on mouse macrophages. J. Immunol. doi: 10.4049/jimmunol.1203167

Lin, M. C., Pan, C. Y., Hui, C. F., Chen, J. Y., and Wu, J. L. (2013). Shrimp anti-lipopolysaccharide factor (SALF), an antimicrobial peptide, inhibits proinflammatory cytokine expressions through the MAPK and NF-kappaB pathways in LPS-induced HeLa cells. Peptides 40, 42-48. doi: 10.1016/j.peptides.2012. 11.010

Liu, H., Yu, H., Gu, Y., Xin, A., Zhang, Y., Diao, H., et al. (2013). Human betadefensin DEFB126 is capable of inhibiting LPS-mediated inflammation. Appl. Microbiol. Biotechnol. 97, 3395-3408. doi: 10.1007/s00253-012-4588-9

Mcgettrick, A. F., and O'Neill, L. A. (2010). Regulators of TLR4 signaling by endotoxins. Subcell. Biochem. 53, 153-171. doi: 10.1007/978-90-481-9078-2_7

Miller, S. I., Ernst, R. K., and Bader, M. W. (2005). LPS, TLR4 and infectious disease diversity. Nat. Rev. Microbiol. 3, 36-46. doi: 10.1038/nrmicro1068

Minetti, C. A., Lin, Y. A., Cislo, T., and Liu, T. Y. (1991). Purification and characterization of an endotoxin-binding protein with protease inhibitory activity from Limulus amebocytes. J. Biol. Chem. 266, 20773-20780.

Mookherjee, N., Lippert, D. N., Hamill, P., Falsafi, R., Nijnik, A., Kindrachuk, J., et al. (2009). Intracellular receptor for human host defense peptide LL-37 in monocytes. J. Immunol. 183, 2688-2696. doi: 10.4049/jimmunol. 0802586

Motzkus, D., Schulz-Maronde, S., Heitland, A., Schulz, A., Forssmann, W. G., Jubner, M., et al. (2006). The novel beta-defensin DEFB123 prevents lipopolysaccharidemediated effects in vitro and in vivo. FASEB J. 20, 1701-1702. doi: 10.1096/fj.054970fje

Nagaoka, I., Hirota, S., Niyonsaba, F., Hirata, M., Adachi, Y., Tamura, H., et al. (2002). Augmentation of the lipopolysaccharide-neutralizing activities of human cathelicidin CAP18/LL-37-derived antimicrobial peptides by replacement with hydrophobic and cationic amino acid residues. Clin. Diagn. Lab. Immunol. 9, 972-982. doi: 10.1128/CDLI.9.5.972-982.2002

Nell, M. J., Tjabringa, G. S., Wafelman, A. R., Verrijk, R., Hiemstra, P. S., Drijfhout, J. W., et al. (2005). Development of novel LL-37 derived antimicrobial peptides with LPS and LTA neutralizing and antimicrobial activities for therapeutic application. Peptides 27, 649-660. doi: 10.1016/j.peptides.2005.09.016

O'Shannessy, D. J., and Wilchek, M. (1990). Immobilization of glycoconjugates by their oligosaccharides: use of hydrazido-derivatized matrices. Anal. Biochem. 191, 1-8. doi: 10.1016/0003-2697(90)90377-L 
Pallarola, D., and Battaglini, F. (2008). An efficient method for conjugation of a lipopolysaccharide from Salmonella enterica sv. Minnesota with probes bearing hydrazine or amino functional groups. Anal. Biochem. 381, 53-58. doi: 10.1016/j.ab.2008.06.008

Pallarola, D., and Battaglini, F. (2009). Surfactant-assisted lipopolysaccharide conjugation employing a cyanopyridinium agent and its application to a competitive assay. Anal. Chem. 81, 3824-3829. doi: 10.1021/ac9001639

Park, S. C., Park, Y., and Hahm, K. S. (2011). The role of antimicrobial peptides in preventing multidrug-resistant bacterial infections and biofilm formation. Int. J. Mol. Sci. 12, 5971-5992. doi: 10.3390/ijms12095971

Piazza, M., Colombo, M., Zanoni, I., Granucci, F., Tortora, P., Weiss, J., et al. (2011). Uniform lipopolysaccharide (LPS)-loaded magnetic nanoparticles for the investigation of LPS-TLR4 signaling. Angew. Chem. Int. Ed. Engl. 50, 622-626. doi: 10.1002/anie.201004655

Pristovsek, P., and Kidric, J. (1999). Solution structure of polymyxins B and E and effect of binding to lipopolysaccharide: an NMR and molecular modeling study. J. Med. Chem. 42, 4604-4613. doi: 10.1021/jm991031b

Pristovsek, P., and Kidric, J. (2001). Peptides neutralizing lipopolysaccharide - structure and function. Mini Rev. Med. Chem. 1, 409-416. doi: 10.2174/1389557013406729

Pulido, D., Nogues, M. V., Boix, E., and Torrent, M. (2012). Lipopolysaccharide neutralization by antimicrobial peptides: a gambit in the innate host defense strategy. J. Innate Immun. 4, 327-336. doi: 10.1159/000336713

Ruberto, F., Ianni, S., Babetto, C., Magnanimi, E., Ferretti, G., Novelli, G., et al. (2013). Polymyxin-B endotoxin removal device: making the point on mechanisms of action, clinical effectiveness and possible future applications: review. Infect. Disord. Drug Targets 13, 128-132. doi: 10.2174/18715265113139990025

Saido-Sakanaka, H., Ishibashi, J., Momotani, E., Amano, F., and Yamakawa, M. (2004). In vitro and in vivo activity of antimicrobial peptides synthesized based on the insect defensin. Peptides 25, 19-27. doi: 10.1016/j.peptides.2003.12.009

Salomao, R., Brunialti, M. K., Rapozo, M. M., Baggio-Zappia, G. L., Galanos, C., and Freudenberg, M. (2012). Bacterial sensing, cell signaling, and modulation of the immune response during sepsis. Shock 38, 227-242. doi: $10.1097 /$ SHK.0b013e318262c4b0

Sawyer, J. G., Martin, N. L., and Hancock, R. E. (1988). Interaction of macrophage cationic proteins with the outer membrane of Pseudomonas aeruginosa. Infect. Immun. 56, 693-698.

Schadich, E., Mason, D., and Cole, A. L. (2013). Neutralization of bacterial endotoxins by frog antimicrobial peptides. Microbiol. Immunol. 57, 159-161. doi: 10.1111/1348-0421.12012

Schulte, W., Bernhagen, J., and Bucala, R. (2013). Cytokines in sepsis: potent immunoregulators and potential therapeutic targets-an updated view. Mediators Inflamm. 2013:165974. doi: 10.1155/2013/165974

Scott, A., Weldon, S., Buchanan, P. J., Schock, B., Ernst, R. K., Mcauley, D. F., et al. (2011). Evaluation of the ability of LL-37 to neutralise LPS in vitro and ex vivo. PLoS ONE 6:e26525. doi: 10.1371/journal.pone.0026525

Scott, M. G., Davidson, D. J., Gold, M. R., Bowdish, D., and Hancock, R. E. (2002). The human antimicrobial peptide LL-37 is a multifunctional modulator of innate immune responses. J. Immunol. 169, 3883-3891.

Scott, M. G., Vreugdenhil, A. C., Buurman, W. A., Hancock, R. E., and Gold, M. R. (2000). Cutting edge: cationic antimicrobial peptides block the binding of lipopolysaccharide (LPS) to LPS binding protein. J. Immunol. 164, 549-553.

Shahriar, F., Gordon, J. R., and Simko, E. (2006). Identification of lipopolysaccharide-binding proteins in porcine milk. Can. J. Vet. Res. 70, 243-250.

Silipo, A., and Molinaro, A. (2011). "Lipid A structure," in Bacterial Lipopolysaccharides: Structure, Chemical Synthesis, Biogenesis and Interaction with Host Cells, eds Y.A. Knirel and M.A. Valvano (New York: Springer-Verlag/Wien), 1-20.
Singh, S., Papareddy, P., Kalle, M., Schmidtchen, A., and Malmsten, M. (2013). Importance of lipopolysaccharide aggregate disruption for the anti-endotoxic effects of heparin cofactor II peptides. Biochim. Biophys. Acta 1828, 2709-2719. doi:10.1016/j.bbamem.2013.06.015

Tack, B. F., Sawai, M. V., Kearney, W. R., Robertson, A. D., Sherman, M. A., Wang, W., et al. (2002). SMAP-29 has two LPS-binding sites and a central hinge. Eur. J. Biochem. 269, 1181-1189. doi: 10.1046/j.0014-2956.2002. 02751.x

Tan, N. S., Ng, M. L., Yau, Y. H., Chong, P. K., Ho, B., and Ding, J. L. (2000). Definition of endotoxin binding sites in horseshoe crab factor $\mathrm{C}$ recombinant sushi proteins and neutralization of endotoxin by sushi peptides. FASEB J. 14, 1801-1813. doi: 10.1096/fj.99-0866com

Tossi, A., Scocchi, M., Skerlavaj, B., and Gennaro, R. (1994). Identification and characterization of a primary antibacterial domain in CAP18, a lipopolysaccharide binding protein from rabbit leukocytes. FEBS Lett. 339, 108-112. doi: 10.1016/0014-5793(94)80395-1

Urh, M., Simpson, D., and Zhao, K. (2009). Affinity chromatography: general methods. Methods Enzymol. 463, 417-438. doi: 10.1016/S0076-6879(09)63026-3

Vaara, M. (2009). New approaches in peptide antibiotics. Curr. Opin. Pharmacol.9, 571-576. doi: 10.1016/j.coph.2009.08.002

Wieczorek, M., Jenssen, H., Kindrachuk, J., Scott, W. R., Elliott, M., Hilpert, K., etal. (2010). Structural studies of a peptide with immune modulating and direct antimicrobial activity. Chem. Biol. 17, 970-980. doi: 10.1016/j.chembiol.2010.07.007

Yu, H., Dong, J., Gu, Y., Liu, H., Xin, A., Shi, H., et al. (2013). The novel human beta-defensin 114 regulates lipopolysaccharide (LPS)-mediated inflammation and protects sperm from motility loss. J. Biol. Chem. 288, 12270-12282. doi: 10.1074/jbc.M112.411884

Yu, L., Tan, M., Ho, B., Ding, J. L., and Wohland, T. (2006). Determination of critical micelle concentrations and aggregation numbers by fluorescence correlation spectroscopy: aggregation of a lipopolysaccharide. Anal. Chim. Acta 556, 216-225. doi: 10.1016/j.aca.2005.09.008

Zasloff, M. (2002). Antimicrobial peptides of multicellular organisms. Nature 415, 389-395. doi: 10.1038/415389a

Zheng, X., Yang, D., Liu, X., Wang, N., Li, B., Cao, H., et al. (2010). Identification of a new anti-LPS agent, geniposide, from Gardenia jasminoides Ellis, and its ability of direct binding and neutralization of lipopolysaccharide in vitro and in vivo. Int. Immunopharmacol. 10, 1209-1219. doi: 10.1016/j.intimp.2010. 07.001

Conflict of Interest Statement: The authors declare that the research was conducted in the absence of any commercial or financial relationships that could be construed as a potential conflict of interest.

Received: 04 October 2013; accepted: 29 November 2013; published online: 17 December 2013.

Citation: López-Abarrategui C, del Monte-Martínez A, Reyes-Acosta O, Franco OL and Otero-González AJ (2013) LPS inmobilization on porous and non-porous supports as an approach for the isolation of anti-LPS host-defense peptides. Front. Microbiol. 4:389. doi: 10.3389/fmicb.2013.00389

This article was submitted to Antimicrobials, Resistance and Chemotherapy, a section of the journal Frontiers in Microbiology.

Copyright (c) 2013 López-Abarrategui, del Monte-Martínez, Reyes-Acosta, Franco and Otero-González. This is an open-access article distributed under the terms of the Creative Commons Attribution License (CC BY). The use, distribution or reproduction in other forums is permitted, provided the original author(s) or licensor are credited and that the original publication in this journal is cited, in accordance with accepted academic practice. No use, distribution or reproduction is permitted which does not comply with these terms. 